\section{Bird Migration.}

A SMALL item which may be of interest to those watching bird migration was noted on a recent voyage to America.

On s.s. St. Louis, of the American Line, about 6.45 p.m. (ship time) on May 3 a swallow came on board, evidently very tired, white breast feathers rather dirty, and, settling down, was caught by one of the passengers. It took some water but died during the night. There was no identification band on either leg.

The point of interest is that the ship was then about $49^{\frac{3}{4}} \mathrm{~N}$. lat. and $23^{\frac{3}{4}} \mathrm{~W}$. long., which would put her some 560 miles west of Cape Clear-about W. by S.and some 680 miles N.W. from Cape Finisterre. The wind had been fairly steady from E.S.E. for the previous thirty hours, blowing 20-30 miles an hour.

The first swallows had been noticed at the place where I now am on Saturday, May I, and no doubt the bird which reached the St. Louis had got separated from the general migration.

The bird seemed in fairly good condition, its brown throat and indigo head were sleek and glossy; the soiled breast feathers may have been due to the steamer's smoke as the bird came in from the lee side.

ED. WILDING.

Dunedin, Jordanstown, Co. Antrim, June 23.

\section{Mercury Ripples showing Interference.}

THE accompanying print of a photograph of mercury ripples showing interference, made in this laboratory, exhibits singularly well the circular waves from the two sources as well as the interference pattern proluced. The two points of disturbance are maintained

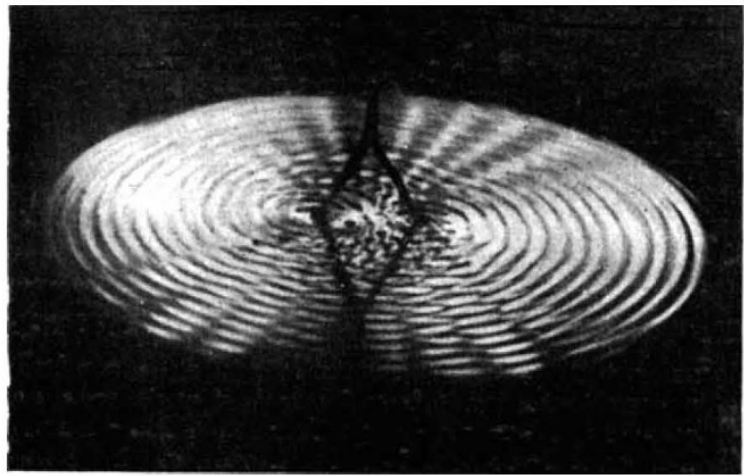

by a forked pointer attached to the prong of a fork of frequency 50 . With daylight illumination from a window, and a rotating sector to render the effect stroboscopic, a good natural picture of the surface is obtained.

Physical Laboratory, Municipal Technical Institute, West Ham, E.

\section{Man's True Thermal Environment.}

I fully agree with Mr. Grabham (Nature, June 24 , p. 45 I) as to the unsuitability of the constanttemperature $\left(37^{\circ}\right.$ C. $)$ psuchrainometer for many parts of the earth's surface. It 'is for this very reason, combined with the advantage of its much greatet simplicity, that I am experimenting with the constant-energy form of instrument mentioned at the end of my former letter (NATURE, May 6, p. 260).

The effect of moisture can be brought into play with any type of psuchrainometer by providing its

$$
\text { NO. } 2384 \text {, VOL. 95] }
$$

exposed surface with a water-wetted muslin cover, and no doubt in this condition the apparatus approximates more closely to the human body.

My interest in the matter, however, is physical rather than physiological. My immediate aim is to study the extent to which " atmospheric cooling" can be predicted from the readings of the existing meteorological instruments. It seems best, therefore, to begin with the simplest case of cooling, namely, that which is free from the thermal complications' accompanying evaporation. James RoberT Milne.

Physical Laboratory, University of Edinburgh, July $x$.

\section{HIGH EXPLOSIVES}

V R. LLOYD - GEORGE'S recent speech in 1 the House of Commons, as Minister of Munitions, emphasised the very important part played by high explosives in the present war. It is essential at the outset to distinguish clearly between a propellent charge, which forces the projectile or shell through the bore of the gun, and the high explosive charge filling the shell itself and causing it to burst, through the intervention of a time or percussion fuse. Modern military propellants consist of gelatinised guncotton (nitro-cellulose), either alone or mixed with varying proportions of nitro-glycerine, pressed into any required shape. The finished explosive is of a colloidal, horny nature, and a piece of it held in the fingers, whilst burning, can be blown out quite easily. A charge lit in the enclosed space of the chamber of a gun can discharge a projectile with a velocity of about Iooo yards per second, developing in the chamber a pressure of, perhaps, twenty tons on the square inch. If the same quantity of the ungelatinised material were ignited in the gun-chamber it would detonate and blow the gun to pieces.

There is thus a wide difference between the effects produced by the burning of a propellant in the open, and in the chamber of the gun. In the latter case, before the projectile begins to move, the gases evolved produce pressure in the chamber, thus greatly accelerating the velocity of the explosive reaction.

The forces at work in the gun, however, are insignificant in comparison with those brought into play when a high explosive detonates. Even in the open, without any containing envelope other than a thin cylinder of paper, the writer has obtained with a high explosive a velocity of detonation of the explosion wave of some seven miles per second. When the high explosive is in an enclosed space, such as a shell, the velocity of the detonation wave is greatly accelerated, and in an almost infinitesimal period of time the explosive is converted into gases. The volume of gases produced varies according to the nature of the explosive, but, generally, for those used in shells, it may be taken that, at the temperature of explosion, the volume of gas evolved occupies from $x_{5}, 000$ to 20,000 times the volume of the original explosive. This is the reason for the enormous destructive and shattering effect of a high explosive. 